\title{
A PIXE, EPMA and SIMS study of the Chainpur meteorite: small grains of lead found in a chondrule
}

\author{
J.L.A.M. Kramer*, A.C. Kik, R.D. Vis \\ Department of Physics and Astronomy, Free University Amsterdam, De Boelelaan 1105, 1081 HV Amsterdam, Netherlands
}

\begin{abstract}
Chondrules in the Chainpur meteorite were studied to determine trace-elemental sitings by means of particle induced $\mathrm{X}$-ray emission (PIXE). One of those, a porphyritic pyroxene-type chondrule, revealed to have an extremely high concentration of lead. The lead concentration tends to be very localized around a spot of about $70 \mu \mathrm{m}$ with a maximum concentration of $5 \mathrm{wt} \%$. Further studies of the same sample revealed other spots of this kind in another type of chondrule.

The porphyritic chondrule was also studied with an electron probe to obtain a better picture of this strange inclusion. This measurement showed that the lead is concentrated in even smaller grains of about $2-4 \mu \mathrm{m}$ in size, incorporated in a glassy groundmass together with enstatite grains. Lead concentrations in these grains are about $50 \mathrm{wt} \%$. Secondary ion mass spectrometry (SIMS) and additional PIXE measurements were done to exclude terrestrial origin of the lead compound. Industrial lead contains up to $6 \mathrm{wt} \%$ antimony, but none was found here with PIXE. Uranium and thorium were not found either above the detection limits of 5 and $18 \mathrm{ppm}$, respectively. The isotopic ratios of the lead isotopes are significantly different from those of common lead. Very convincing is the fact that the isotopic ratios fall in the same ball park as the ratios found in other meteorites of the same kind. This very strongly suggests that contamination can be ruled out.

Assuming the single-stage model to be valid for this kind of meteorite, the ratio $\mu={ }^{204} \mathrm{~Pb} /{ }^{238} \mathrm{U}$ is determined from the ${ }^{207} \mathrm{~Pb} /{ }^{204} \mathrm{~Pb}$ versus ${ }^{206} \mathrm{~Pb} /{ }^{204} \mathrm{~Pb}$ diagram and found to be around 6.5. Because no uranium was found in concentrations suggested by this ratio, it is likely that a recent metamorphic event separated the lead from its source region. A probable source region could be the troilite-rich rim which surrounds the chondrule. A candidate for the recent metamorphic event is the collisional break-up of the parent body of the meteorite, roughly 500-650 Myr ago.
\end{abstract}

\section{Introduction}

The Chainpur meteorite fell as a shower of stones on 9th May 1907, near the village of Chainpur, India [1]. Chainpur belongs to the largest group of stony meteorites: the ordinary chondrites $[2,3]$. The chondrites are named after their most abundant constituent, chondrules. Although there is yet no consensus among the meteoriticists how to define chondrules [4], they are formed as an isolated droplet of molten or partially molten material [5]. The fine grained material around these mostly'round objects is called the matrix. Matrix in Chainpur is highly porous and clastic, the grains are less than $0.1 \mu \mathrm{m}$ of densely packed olivine $\left(\mathrm{Fa}_{50}\right)$ [6]. The major phases occurring in chondrites are anhydrous fer-

\footnotetext{
* Corresponding author.
}

romagnesian silicates (olivines and pyroxenes), sulfides (mostly FeS also known as troilite), some oxides and metal (Ni-Fe alloys). Roughly, one can divide chondrules into two categories on the basis of their texture in thin sections. The largest group in number, the porphyritic chondrules $[7,8]$, consists of relatively large phenocrysts. Phenocrysts in chondrites are clear distinctive mineral grains from olivine or pyroxene in a glassy mesostatis. The mesostatis has a feldspathic composition. The other category, the nonporphyritic chondrules, is composed of barred olivine, radial pyroxene and granular chondrules. Around some chondrules also coarse or fine grained rims do occur $[9,10]$. See Fig. 1 for an example of a Chainpur porphyritic chondrule with a fine grained rim.

In 1964, Klaus Keil et al. [11] demonstrated the unusual variability in composition of olivine and pyroxene in the chondrules of Chainpur. He concluded that individual silicate grains within single chondrules are not in 


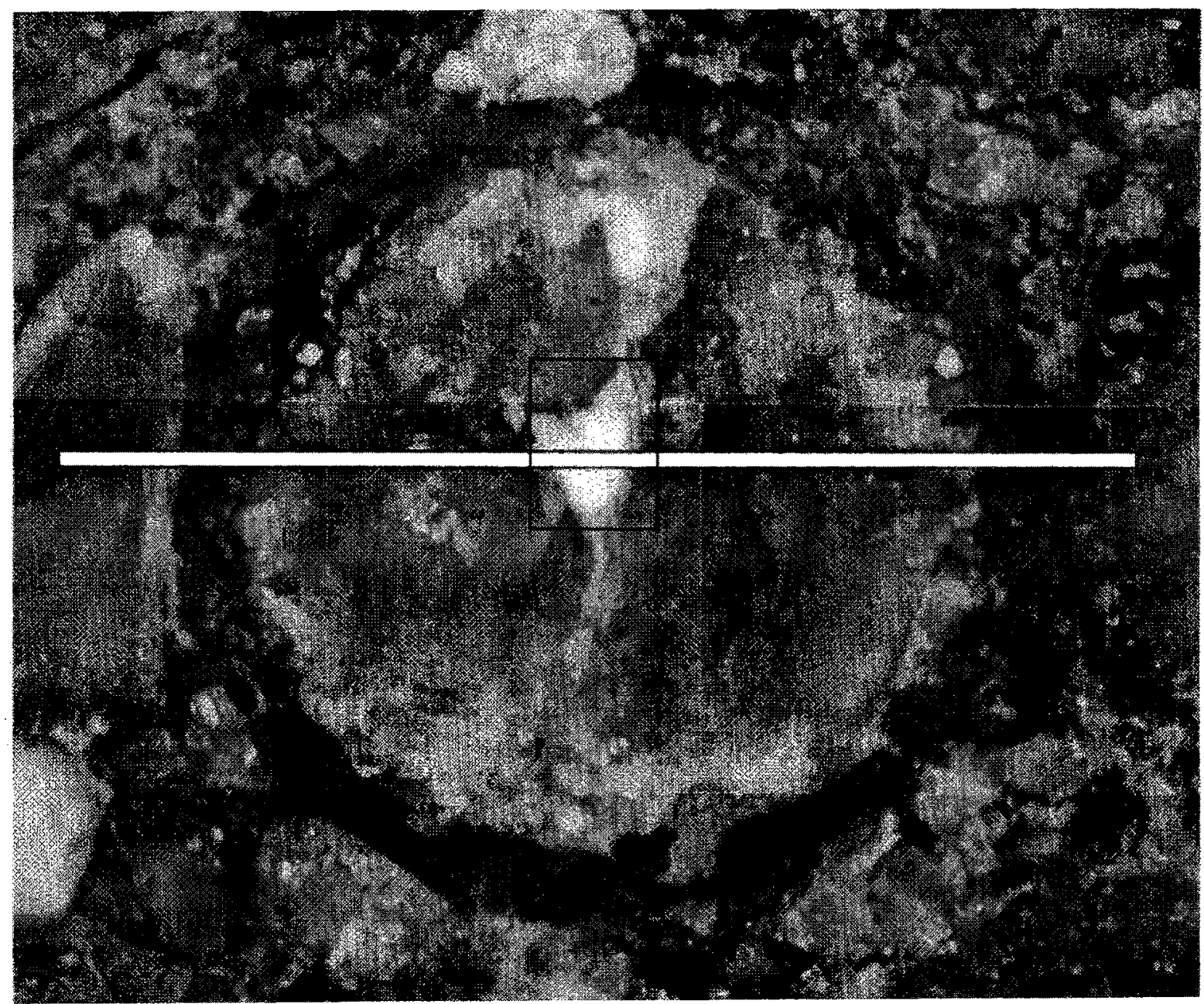

Fig. 1. Reflected-light micrograph of a Chainpur porphyritic chondrule with a fine grained rim containing small troilite and metal grains. Chondrule size of about $700 \mu \mathrm{m}$. Fat white line indicates the position of the PIXE measurements. Black rectangle defines the area of the electron probe and SIMS measurements.

equilibrium, as a conscquence of either rapid crystallization or of crystallization at temperatures too low to allow diffusion to eliminate the compositional variation. The clear difference between unequilibrated and equilibrated chondrites is now recognized. In the modern classification scheme, Chainpur belongs to the ordinary chondrites with the chemical classification LL, that means low in iron and low in metal. Its petrologic type is 3.4 [12], which means that Chainpur has suffered little or no metamorphism after the formation of the meteorite. All unequilibrated chondrites suffered only a very mild thermal metamorphism [13]. Meteorites of this chemicalpetrologic group carry huge amounts of information about the early history of our solar system [14] and give us clues about chondrule formation. Volatile elements play a key role in unravelling the thermal history of the chondrites and provide important constraints for the mechanism of accretion of protoplanetary material. Little is yet known about volatile element sitings in ordinary chondrites because most of them are present on trace elemental concentrations $[15,16]$.

The goal of our research is, by means of particle induced X-ray emission (PIXE), to gain more knowledge about the volatile elemental sitings. Lead is such a highly volatile element, although occurring at average bulk concentration of $1 \mathrm{ppm}$ in chondrites [17], it was found in an extreme high concentration, up to $50 \mathrm{wt} \%$, in a porphyritic chondrule. Much care was taken to prevent and rule out contamination. For that, additional electron probe (EPMA) and secondary ion mass spectrometry (SIMS) measurements have been prcformed. Two more of these chondrules with this strange lead compound have been found with PIXE, but not studied as rigorously as the one depicted in Fig. 1. 


\section{Measurements}

\subsection{PIXE}

The porphyritic pyroxene chondrule with a very beautiful fine grained rim, depicted in Fig. 1, was studied using PIXE. A relatively broad proton beam of $8 \times 20 \mu \mathrm{m}$ with an energy of $3.5 \mathrm{meV}$ was used. The results of a $1000 \mu \mathrm{m}$ scan from one edge of the chondrule, including the rim and some of the matrix, to the other edge is plotted in Figs. 2 and 3. The position of this scan is marked in Fig. 1 with a fat white line. From the sulphur, nickel and iron distributions it is clearly seen that the rim contains some troilite and metal grains. These grains are also very easily determined by means of an optical research microscope. The elevations of calcium concentration as seen in the chondrule indicates the calcium-rich mesostasis, in contrast with the low calcium pyroxene of the phenocrysts. Almost in the middle of the scan, at $550 \mu \mathrm{m}$, an extremely high concentration of lead was found. This region is strongly depleted in silicon, but somewhat enriched in calcium. One very obvious candidate for a lead bearing mineral is galena $(\mathrm{PbS})$, but because of the $\mathrm{M}$

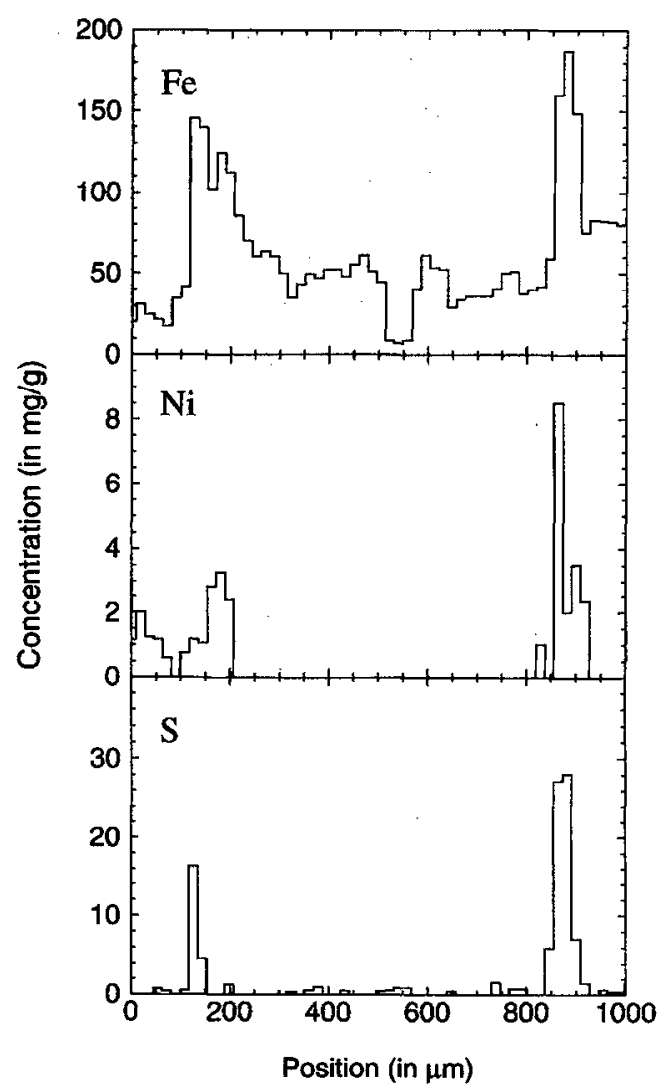

Fig. 2. Elemental distributions of iron, nickel and sulphur with PIXE on the Chainpur chondrule as depicted in Fig. 1.
X-ray line interference of lead with the K-line of sulphur, it was not possible to determine this with PIXE.

However, contamination is always of a major concern when studying lead. Therefore, additional electron probe measurements were done to study this spot more extensively. Also SIMS measurements were performed to measure the isotopic ratios of the lead inclusion. The reasons therefore are twofold. The isotopic ratios of lead in chondrites differ from those found in rocks on Earth because they have not been exposed to heavy metamorphism resulting in fractionation between uranium, thorium and lead. From thesc isotopic data, onc can also draw conclusions concerned with the age and thermal history of the chondrule. Further PIXE measurements were performed to find more of these chondrules with the same kind of lead inclusions. Two were found in the same sample, one other porphyritic chondrule and one radial pyroxene chondrule. Unfortunately, these chondrules have not been studied with SIMS or EPMA. A new sample of chainpur has been obtained from Rice University, Houston, and is prepared for new experiments in the future.

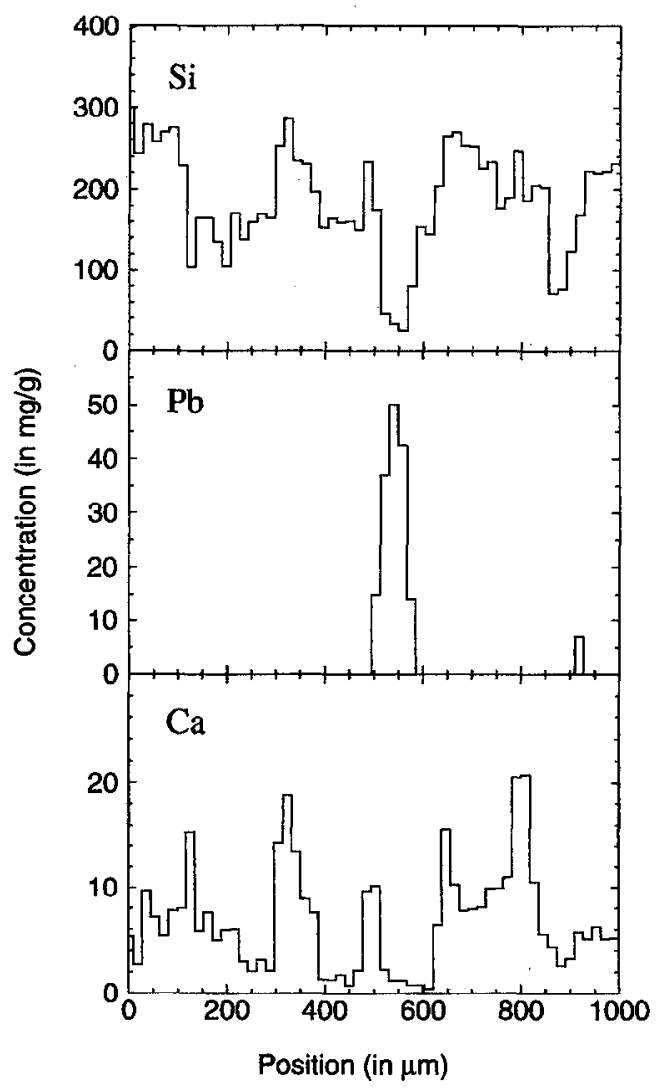

Fig. 3. Elemental distributions of silicon, lead and calcium measured with PIXE on the Chainpur chondrule as depicted in Fig. 1. 


\section{2. $E P M A$}

The mineralogy of the lead inclusion and neighbouring minerals was studied with the electron microprobe at Rice University in Houston. Table 1 displays the results

Table 1

PIXE and EPMA results

\begin{tabular}{lclr}
\hline Lead spot & \multicolumn{3}{l}{ Nearby mineral } \\
\hline $\mathrm{Si}$ & $17.0 \%$ & $\mathrm{MgO}$ & $35.6 \%$ \\
$\mathrm{Fe}$ & $0.7 \%$ & $\mathrm{SiO}_{2}$ & $57.6 \%$ \\
$\mathrm{~Pb}$ & $49.9 \%$ & $\mathrm{FeO}$ & $4.5 \%$ \\
$\mathrm{Zn}$ & $58.7^{\mathrm{a}} \mathrm{ppm}$ & $\mathrm{CaO}$ & $2.0 \%$ \\
$\mathrm{Rb}$ & $6.0^{\mathrm{a}} \mathrm{ppm}$ & $\mathrm{MnO}$ & $0.28 \%$ \\
$\mathrm{Sr}$ & $22.4^{\mathrm{a}} \mathrm{ppm}$ & & \\
$\mathrm{Zr}$ & $267.0^{\mathrm{a}} \mathrm{ppm}$ & & \\
$\mathrm{Th}$ & $<18.0^{\mathrm{a}} \mathrm{ppm}$ & & \\
$\mathrm{U}$ & $<5.0^{\mathrm{a}} \mathrm{ppm}$ & & \\
\hline
\end{tabular}

${ }^{\text {a }}$ PIXE measurements. and Fig. 4 shows a backscattered electron image of this region. In the backscattered electron image small lead grains of about $4 \mu \mathrm{m}$ can be seen. These grains can also be seen with an optical microscope (see Fig. 5) showing that these grains are really a part of the chondrule instead of a surface pollution. The EPMA data further reveals that the lcad is concentrated even in much higher concentrations, something close to $50 \mathrm{wt} \%$ has been found. The nearby minerals, embedded in a glassy mesostatis, are mainly enstatite (magnesium-rich pyroxene). It was not established what the exact mineral composition of the lead compound is. In Table 1 also some PIXE results are incorporated. Special attention should be paid to the fact that there is no significant amount of thorium or uranium present.

\subsection{SIMS}

The SIMS measurements were performed at the Shell Laboratory in Amsterdam. The SIMS data are corrected

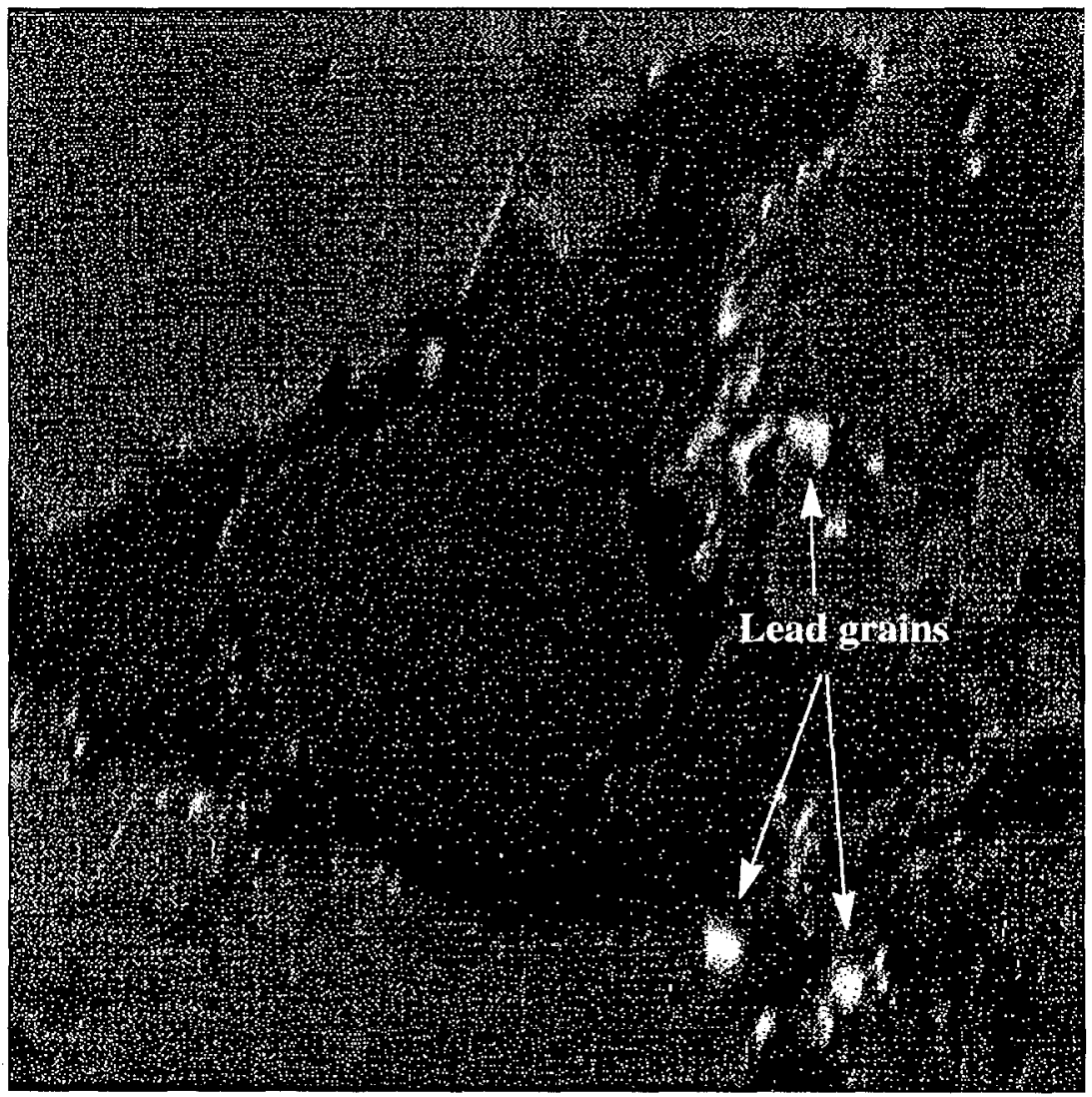

$20 \mathrm{um}$

Fig. 4. Backscattered scanning electron micrograph showing little grains of lead found by the PIXE experiments. 


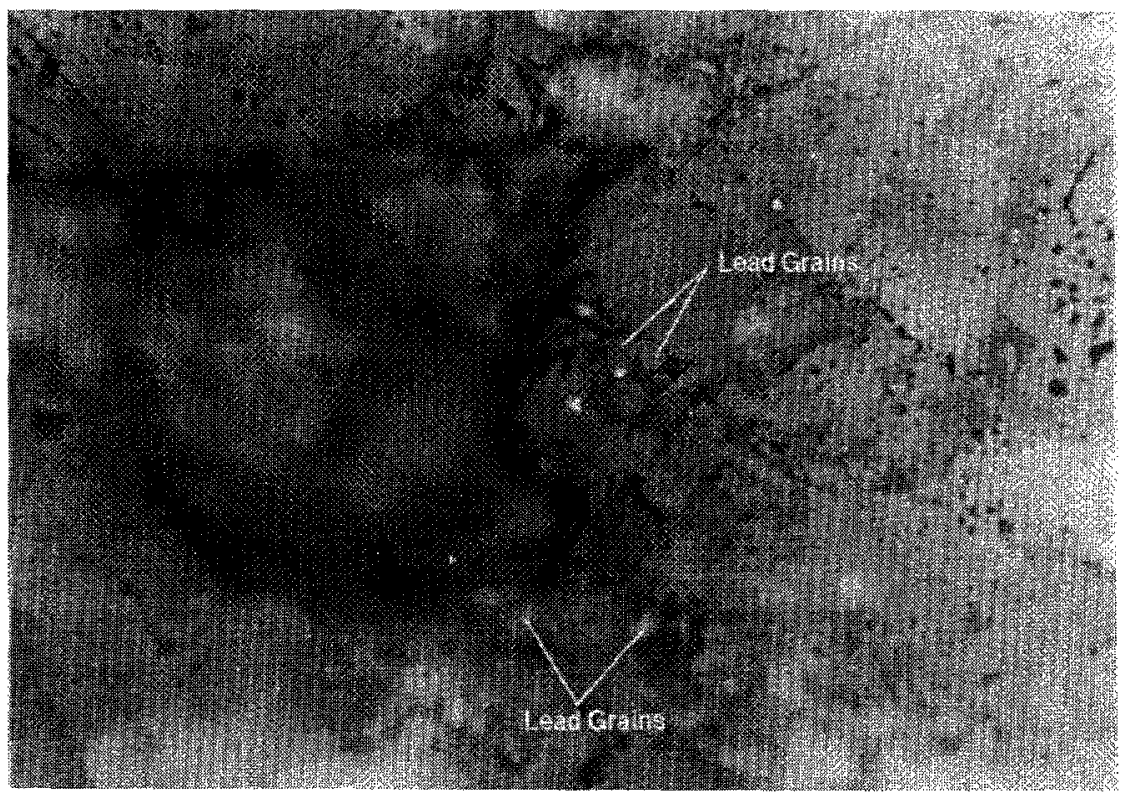

Fig. 5. Reflected light micrograph showing various enstatite grains in a glassy mesostatis. The lead grains in the middle are clearly visible, the ones at the lower part of the photograph are out of focus.

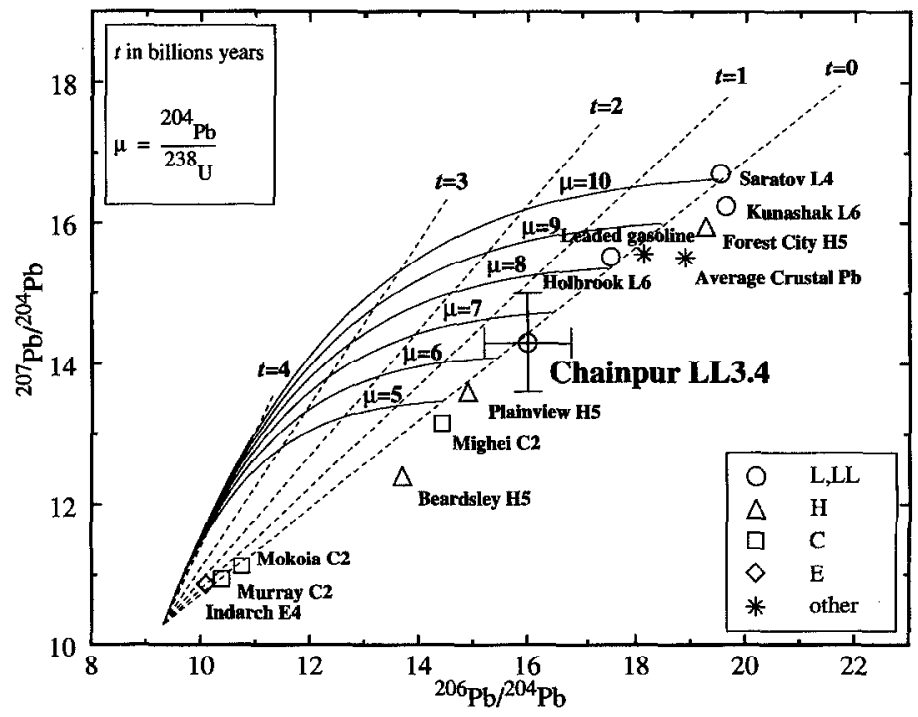

Fig. 6. ${ }^{207} \mathrm{~Pb} /{ }^{204} \mathrm{~Pb}$ versus ${ }^{206} \mathrm{~Pb} /{ }^{204} \mathrm{~Pb}$ isotope correlation diagram. Straight dashed lines are isochrons, solid curved lines are growth curves. Isotopic ratios of various chondrites of different chemical-petrologic types are plotted together with the Chainpur data of this research. Also ratios of average crustal lead and leaded gasoline are plotted.

with a lead sample with known isotopic ratios. The measured isotopic ratios ${ }^{206} \mathrm{~Pb} /{ }^{204} \mathrm{~Pb}=16.0 \pm 0.7$ and ${ }^{207} \mathrm{~Pb} /{ }^{204} \mathrm{~Pb}=14.3 \pm 0.6$ are depicted in Fig. 6 together with data obtained from other chondrites (chemical groups L, LL, H, C and E) [17]. Values for average crustal lead are also plotted in this ${ }^{207} \mathrm{~Pb} /{ }^{204} \mathrm{~Pb}$ versus
${ }^{206} \mathrm{~Pb} /{ }^{204} \mathrm{~Pb}$ diagram. These ratios are obtained from the Stacey and Kramers model [18]. The difference between the Chainpur data and terrestrial lead, as displayed in this diagram, is very evident. In the next section more implications from the isotope data of lead will be discussed. 


\section{The common lead method of dating}

From isotopic compositions of lead, uranium and thorium, three independent ages can be determined. If, however, only the lead isotopic composition is known, then it is still possible to determine a formation age. This is called the common-lead method of radiogenic dating. The ages determined this way are model ages and are called $\mathrm{Pb}-\mathrm{Pb}$ ages. For chondrites the single stage model applies well [19]. This model assumes that all lead samples of common lead are mixtures of radiogenic lead, that formed in closed regions, with primeval lcad.

Lead has four naturally occurring stable isotopes: ${ }^{204} \mathrm{~Pb},{ }^{206} \mathrm{~Pb},{ }^{207} \mathrm{~Pb}$ and ${ }^{208} \mathrm{~Pb} .{ }^{204} \mathrm{~Pb}$ is the only lead isotope that is not radiogenic and is used for normalization. ${ }^{206} \mathrm{~Pb},{ }^{207} \mathrm{~Pb}$ and ${ }^{208} \mathrm{~Pb}$ can be produced by decay of ${ }^{238} \mathrm{U},{ }^{235} \mathrm{U}$ and ${ }^{232} \mathrm{Th}$, respectively. The primeval isotope ratios of lead are determined from the Canyon Diablo iron meteorite in troilite $[20,21]$. The atomic ratio ${ }^{238} \mathrm{U} /{ }^{235} \mathrm{U}=137.88$ and decay constants of ${ }^{235} \mathrm{U}$ and ${ }^{238} \mathrm{U}$ were adopted from Ref. [22]. In the common-lead method, the isotopic ratios are depicted in a ${ }^{207} \mathrm{~Pb} /{ }^{204} \mathrm{~Pb}$ versus ${ }^{206} \mathrm{~Pb} /{ }^{204} \mathrm{~Pb}$ diagram. The dashed straight lines are isochrons. All single-stage leads that were removed from their sources at the same time must lie on such line. Obviously $t=0$, also called the geochron, means that the lead has not been removed from its source. The curved lines are the growth curves for different present-day $\mu={ }^{204} \mathrm{~Pb} /{ }^{208} \mathrm{~Pb}$ ratios. This is the path radiogenic lead went through after crystallization and before an eventually separation from its host mineral.

From Fig. 6, assuming that the single-stage model is to be correct, the $\mathrm{Pb}-\mathrm{Pb}$ age of the mineral can be determined. The Chainpur data are quite near the geochron. So its age is pretty close to $4.55-4.57 \mathrm{Gyr}$, the age of our solar system. It should be noted that the common-lead method is not very sensitive to recent metamorphic events. Other radiogenic clocks are available for obtaining that kind of information. Also the present-day $\mu={ }^{204} \mathrm{~Pb} /{ }^{238} \mathrm{~Pb}$ ratio can be determined. It turns out to be around 6.5. From this figure and from the lead concentration, the uranium concentration can be estimated.

\section{Discussion}

From Fig. 6 it is clear that the isotopic ratio of the lead grain in chainpur is quite different than those of terrestrial leads. Secondly, the chainpur data point is very near on the geochron like all other chondrites. The lead grain is thus quite normal radiogenic. Comparing the backscattered electron image with the optical microscope picture shows beautifully the correlation betwecn the grain seen on the photograph and the spots found with the electron probe. The only problem is caused by the $\mu$ value of 6.5 and the low uranium concentration, if present at all, found by PIXE. The only casual explanation is that a recent metamorphic event separated the lead from its source region.

The data from the electron probe and SIMS measurements are very convincing and the possibility of contamination from laboratory origin can be excluded. In general, industrial lead contains about $6 \mathrm{wt} \%$ antimony. But neither with PIXE nor with EPMA, any trace of antimony was found. Being able to identify positively the grains with the optical microscope is very convincing.

Because chondrules are to be the high-temperature phases in chondrites [23], a highly volatile element like lead is not expected to be found there. Therefore, it is likely that a recent violent shock metamorphic event has redistributed the lead and separated it from its source region. The impact on earth of the meteorite could be one option. But the much more violent break-up of the meteorite parent bodies roughly 500-650 Myr ago [24], is much more likely. The pressure caused by the collision between the parent bodies could have cracked the chondrule and heated it sufficiently to get the lead mobilized [25]. This idea can be checked with the ${ }^{40} \mathrm{Ar}-{ }^{39} \mathrm{Ar}$ clock, which records such events. A probable source could be the troilite (or may be even metal [26]) in the rim around the chondrule. It is known that lead concentrations are some what higher ( $5 \mathrm{ppm}$ ) in troilite than bulk concentrations [27]. The reason why lead moved into the chondrule, instead of into the porous matrix, is not explained satisfactorily yet. May be the glassy feldspathic mesostatis is a better medium for transportation of lead than the densely packed olivine of the matrix. Of course, a lot of troilite (about $2 \mu \mathrm{g}$ to form $1 \mu^{3} \mathrm{PbO}$ ) has to be present in the rim and it should be depleted in lead by now.

\section{Acknowledgements}

We thank D. Heymann for making it possible to do the necessarily electron probe measurements at Rice University, Houston and for the supply of the meteorite samples. From the Shell laboratory in Amsterdam, we thank W. Koot and C. van der Spek for doing the SIMS measurements.

\section{References}

[1] G.P. Cotter, Records Geol, Surv. India 42 (1912) 265

[2] W.R. Van Schmus and J.A. Wood Geochim. Cosmochim. Acta. 31 (1967) 747-765.

[3] D.W.G. Sears and R.T. Dodd, Meteorites and the Early Solar System (Univ. of Arizona Press, Arizona, 1988) p. 3-31.

[4] J.N. Grossman and J.T. Wasson, Chondrules and their Origins (Lunar and Planetary Institute, Houston, 1983) p. $88-121$. 
[5] G.J. Mac-Pherson and L. Grossman, Papers Presented to the Conf. on Chondrules and their Origin (The Lunar and Planetary Institute, Houston, 1982) p. 43-44.

[6] E.R.D. Scott, D.J. Barber, C.M. Alexander, R. Hutchison and J.A. Peck, Meteorites and the Early Solar System, (Univ. of Arizona Press, Arizona, 1988) p. 718-745.

[7] J.L. Gooding and K. Keil, Meteoritics 16 (1981) 17-43.

[8] J.N. Grossman, A.E. Rubin, H. Nagahara and E.A. King Meteorites and the Early Solar System (Univ. of Arizona Press, Arizona, 1988) p. 619-659.

[9] C.M.O. Alexander, R. Hutchison and D.J. Barber, Earth Planet. Sci. Lett. 95 (1989) 187-207.

[10] A.E. Rubin, Geochim. Cosmochim. Acta. 48 (1984) 1779-1789.

[11] K. Keil, B. Manson, H.B. Wiik and K. Fredriksson, Am. Museum Novitates 2173 (1964) 1.

[12] D.W.G. Sears and K.S. Weeks, Proc. 14th Lunar and Planetary Science Conf. J. Geophys. Res., 88 (1983) B301-B311.

[13] G.R. Huss, K. Keil and G.J. Taylor, Geochim. Cosmochim. Acta. 45 (1981) 33-51.

[14] J.N. Grossman and J.W. Wasson, Geochim. Cosmochim. Acta. 46 (1982) 1081-1099.

[15] J.N. Grossman, A. Kracher and J.T. Watson, Geophys. Res. Lett. 6 (1979) 597-600.
[16] M.E. Lipschutz and D.S. Woolum, Meteorites and the Early Solar System (Univ. of Arizona Press, Arizona, 1988) $462-487$.

[17] B. Mason (ed.), Handbook of Elemental Abundances in Meteorites (Gordon \& Breach, London, 1971).

[18] J.S. Stacey and J.D. Kramers, Earth Planet. Sci. Lett. 26 (1975) 207-221.

[19] M. Tatsumoto, R.J. Knight and C.J. Allègre, Science 180 (1973) 1279-1283.

[20] J.H. Chen and G.J. Wasserburg, Lunar Planet. Sci. XIV (1983) 435-436.

[21] J.H. Chen and G.J. Wasserburg Geochim. Cosmochim. Acta. 47 (1983) 1725-1737.

[22] R.H. Steiger and E. Jäger, Earth Planet. Sci. Lett. 36 (1977) 359-362.

[23] E. Andres, Accounts Chem. Res. 1 (1968) 289-298.

[24] D. Heymann, Icarus 6 (1967) 189-221.

[25] T.M. Walsh and M.E. Lipschutz, Geochim. Cosmochim. Acta. 46 (1982) 2491-2500.

[26] D.S. Woolum and D.S. Burnett, Geochim. Cosmochim. Acta. 45 (1981) 1619-1632.

[27] K.H. Wedepohl, Handbook of Geochemistry, Sections C-D, II-5, ch. 82. (Springer, Heidelberg, 1974). 